\title{
Erratum to: VLSI: Systems on a Chip
}

\author{
Luis Miguel Silveira ${ }^{1}$, Srinivas Devadas ${ }^{2}$, and Ricardo Reis ${ }^{3}$ \\ 1 INESC, Portugal \\ 2 Massachusetts Institute of Technology, USA \\ 3 Universidade Federal do Rio Grande do Sul, Brazil
}

\section{Erratum to: \\ L.M. Silveira et al. (Eds.) \\ VLSI: Systems on a Chip \\ DOI: $10.1007 / 978-0-387-35498-9$}

The book was inadvertently published with an incorrect name of the copyright holder. The name of the copyright holder for this book is: (c) IFIP International Federation for Information Processing. The book has been updated with the changes.

The updated original online version for this book can be found at DOI: $10.1007 / 978-0-387-35498-9$ 